\title{
Pemberdayaan Keluarga tentang Kemandirian Lansia dalam Pemenuhan Aktivitas Sehari-Hari di Posyandu Lansia Rindang Benua Wilayah Kerja Puskesmas Pahandut Palangka Raya
}

\author{
Family Empowerment regarding the Independence of the Elderly in Fulfilling Daily Activities \\ at the Rindang Benua Elderly Posyandu in the Work Area of Pahandut Palangka Raya \\ Community Health Center
}

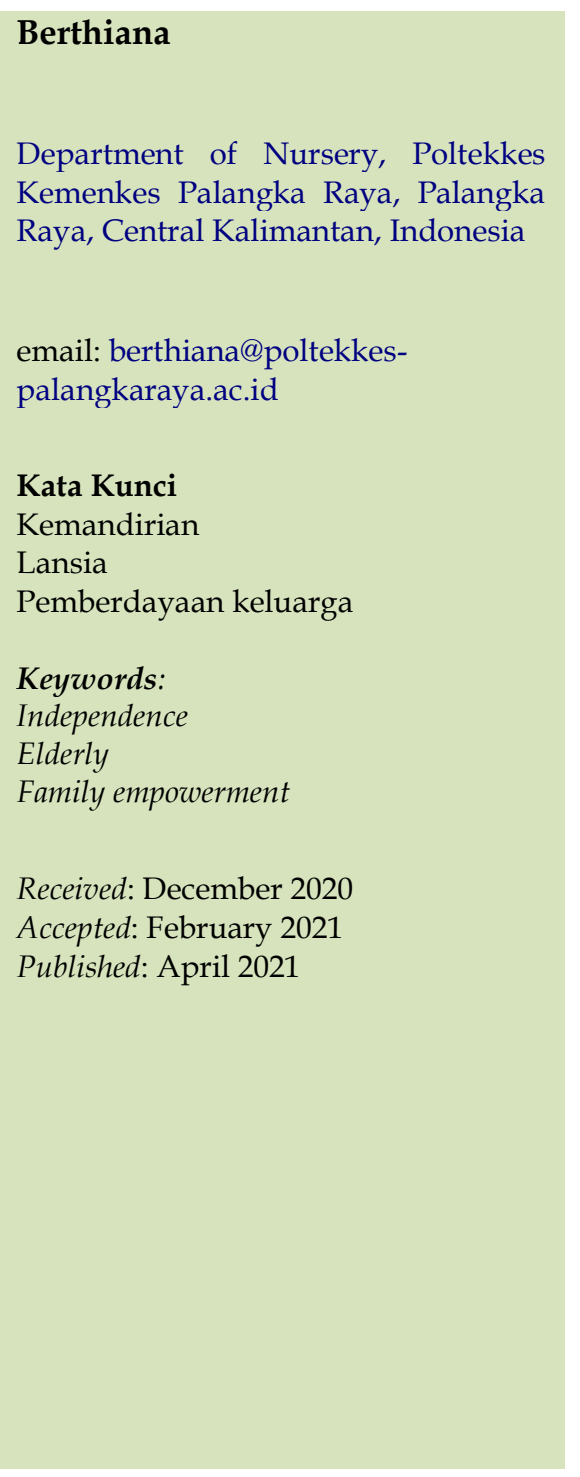

\begin{abstract}
Abstrak
Penduduk usia lanjut perlu diberi perhatian karena biasanya pada usia lanjut akan timbul banyak keluhan/masalah kesehatan karena turunnya fungsi organ tubuh, oleh karena itu perlu berbagai dukungan dari berbagai pihak terutama keluarga dalam meningkatkan kemandirian lansia dalam pemenuhan aktifitas ssehari-hari agar lansia dapat mempertahankan kesehatannya seoptimal mungkin. Hasil penelitian menunjukkan peningkatan pengetahuan mengenai dukungan keluarga yang baik serta kesadaran lansia dalam kemandirian melakukan aktifitas sehari-hari akan meningkatkan kualitas hidup lansia dalam masa tuanya. Evaluasi yang dilakukan dalam pengabdian masyarakat ini ada dua yaitu: Evaluasi pre tes dan post tes yaitu pada kegiatan hasil pretes dari 30 peserta hasil $45 \%$ baik dan $55 \%$ kurang baik setelah proses kegiatan dilakukan post tes memperoleh nilai $90 \%$ baik dan 10\% kurang baik. Kesimpulan dari pelaksanaan pengabdian masyarakat peserta dalam kegiatan pengabdian masyarakat dapat mengerti dan memahami peran keluarga tentang kemandirian lansia dalam pemenuhan aktifitas seharihari.
\end{abstract}

\begin{abstract}
Elderly residents need to be given attention because usually, at old age, there will be many complaints/health problems due to decreased organ function. Therefore it needs various supports from various parties, especially families, in increasing the independence of the elderly in fulfilling daily activities so that the elderly can maintain their health as optimal as possible. The results showed that increased knowledge about good family support and awareness of the elderly in doing their own independent activities would improve the quality of life of the elderly in their old age. There are two evaluations carried out in this community service: pre-test and post-test evaluation. For the pre-test results of 30 participants, $45 \%$ are good, and $55 \%$ are not good after the activity process is carried out; the post-test gets $90 \%$ good and $10 \%$ less good. The conclusion from the implementation of community service participants in community service activities can understand and understand the role of the family regarding the independence of the elderly in fulfilling daily activities.
\end{abstract} Palangkaraya. This is Open Access article under the CC-BY-SA License (http://creativecommons.org/licenses/by-sa/4.0/). DOI: https://doi.org/10.33084/pengabdianmu.v6i3.1923

\section{PENDAHULUAN}

Lanjut usia (lansia) adalah orang yang telah mencapai usia 60 tahun ke atas yang mempunyai hak yang sama dalam kehidupan bermasyarakat, berbangsa, dan bernegara. Sekarang jumlah lansia semakin meningkat, oleh karena itu pemerintah telah merumuskan berbagai kebijakan pelayanan kesehatan usia lanjut ditujukan untuk meningkatkan derajat kesehatan dan mutu 
kehidupan lansia untuk mencapai masa tua bahagia dan berdaya guna dalam kehidupan keluarga dan masyarakat sesuai dengan keberadaannya (Misnaniarti, 2017).

Majunya dunia keperawatan berdampak pada meningkatnya harapan hidup masyarakat yang mengakibatkan banyaknya lanjut usia yang membutukkan pelayanan kesehatan dan pelayanan keperawatan lanjut usia yang professional (Pramono \& Fanumbi, 2012). Pembangunan kesehatan meningkat diberbagai bidang di Indonesia telah mewujudkan peningkatan kualitas kesehatan penduduk. Salah satu outcome atau dampak dari keberhasilan pembangunan nasional dibidang kesehatan dan kesejahteraan sosial dirasakan antara lain adalah meningkatnya angka ratarata harapan hidup (Kushariyadi, 2010).

Peningkatan rata-rata harapan hidup tersebut mencerminkan bertambah panjangnya masa hidup penduduk lansia, pada abad 21 bagi bangsa Indonesia merupakan abad lanjut usia (era of population ageing), karena pertumbuhan penduduk lansia di Indonesia diperkirakan lebih cepat dibandingkan dengan Negara Negara lain. Pada tahun 2010 jumlah penduduk lansia di Indonesia berkisar 9,77\% dari total jumlah penduduk (Badan Pusat Statistik, 2010). Diperkirakan tahun 2020 jumlah lansia di Indonesia akan meningkat mencapai $11,34 \%$ atau tercatat 28,8 juta orang dari seluruh populasi. Melihat tingkat kesehatan dan kesejahteraan kian membaik maka angka harapan hidup penduduk Indonesia juga kian meningkat (Ginting \& Brahmana, 2019). Berdasarkan data Badan Pusat Statistik (BPS) tahun 2007, jumlah lansia di Indonesia mencapai 18,96 juta jiwa. Dari jumlah tersebut 14\% diantaranya berada di Daerah Istimewa Yogyakarta atau yang tertinggi di Indonesia disusul Jawa Tengah (11,16\%), Jawa Timur $(11,14 \%)$, dan Bali (11,01\%) (Kresnawati \& Kartinah, 2012).
Berdasarkan sensus penduduk tahun 2016 di Kalimantan Tengah jumlah lansia sebanyak 141.400 jiwa atau $5,54 \%$ dari total jumlah penduduk provinsi Kalimantan Tengah. Penduduk usia lanjut perlu diberi perhatian karena biasanya pada usia lanjut akan timbul banyak keluhan/masalah kesehatan karena turunnya fungsi organ tubuh, oleh karena itu baik pelayanan maupun fasilitas kesehatan juga harus memperhatikan kebutuhan usia lanjut (Kurnianto, 2015).

Berbagai upaya telah dilakukan oleh instansi pemerintah, para profesional kesehatan, serta bekerja sama dengan pihak swasta dan masyarakat untuk mengurangi angka kesakitan (morbiditas) dan kematian (mortalitas) lansia (Yuningsih, 2019). Pelayanan kesehatan, sosial, dan ketenagakerjaan, dan lain-lainnya telah dikerjakan pada berbagai tingkatan, yaitu tingkat individu lansia, kelompok lansia, keluarga. Panti Sosial Tresna Werda (PSTW), Sarana Tresna Werda (STW), Sarana Pelayanan Kesehatan Tingkat Dasar (primer), Saran Pelayanan Kesehatan Rujukan Tinngkat Pertama (sekunder), dan Sarana Pelayanan Kesehatan Tingkat Lanjutan (tersier) untuk mengatasi permasalahan yang terjadi pada lansia (Maryam et al., 2010).

Masyarakat kita saat ini memandang para lanjut usia sebagai orang-orang yang kurang produktif, kurang menarik, kurang energik, mudah lupa, barangkali kurang bernilai dibandingkan dengan mereka yang masih dalam keadaan prima (Sulandari et al., 2009). Dalam pembangunan nasional pemerintah telah berhasil mewujudkan hasil yang positif diberbagai bidang, yaitu adanya kemajuan ekonomi, perbaikan lingkungan hidup, kemajuan ilmu pengetahuan dan teknologi, terutama di bidang medis atau ilmu kedokteran, sehingga dapat meningkatkan kualitas kesehatan penduduk serta meningkatkan umur harapan hidup manusia. Akibatnya jumlah penduduk yang berusia lanjut meningkat dan bertambah cenderung 
lebih cepat atau sering disebut dengan lansia booming (Affandi, 2009).

Permasalahan yang dihadapi oleh lansia adalah Penyakit pada lanjut usia sering berbeda dengan pada dewasa muda, karena penyakit pada lansia merupakan gabungan dari kelainan-kelainan yang timbul akibat penyakit dan proses menua, yaitu proses menghilangnya secara perlahan-lahan kemampuan jaringan untuk memperbaiki diri atau mengganti diri serta mempertahankan struktur dan fungsi normalnya, sehingga tidak dapat bertahan terhadap jejas (termasuk infeksi) dan memperbaiki kerusakan yang diderita (Afrizal, 2018).

Berdasarkan uraian tersebut, maka perumusan masalah dalam kegiatan ini adalah pendidikan kesehatan tentang kemandirian lansia dalam pemenuhan aktifitas seharihari. Kegiatan pengabdian masyarakat ini salah satunya adalah pembinaan lansia, sebagai upaya dengan menjaga kesehatan dan kesejahteraan agar lansia dapat mempertahankan kualitas hidupnya agar lebih baik. Kegiatan pengabdian masyarakat ini juga merupakan salah satu tuntutan dari Tri Darma Perguruan Tinggi dimana setiap dosen diwajibkan untuk melaksanakan pengabdian kepada masyarakat.

Kegiatan pengabdian masyarakat akan dilaksanakan di Posyandu Lansia Rindang Banua Wilayah Kerja Puskesmas Pahandut. Jumlah lansia di Posyandu Rindang Banua sebanyak 50 orang dimana gambaran kesehatan Lansia di Posyandu tersebut kebanyakkan mengalami penyakit degeneratif seperti Hipertensi, DM, asam urat dan lain-lain. Tujuan dari kegiatan pengabdian ini adalah untuk meningkatkan kemampuan keluarga dalam memenuhi kemandirian lansia pada pemenuhan aktifitas sehari-hari di Posyandu Lansia Rindang Benua wilayah kerja Puskesmas Pahandut Kota Palangka Raya.

\section{METODOLOGI}

Kegiatan pengabdian masyarakat dilaksanakan pada hari Selasa, 5 November 2019 di Posyandu Lansia Rindang Benua Wilayah Kerja Puskesmas Pahandut Kota Palangka Raya. Kegiatan pengabdian kepada masyarakat yang dilakukan ini secara teknis melibatkan kerjasama antara institusi Poltekkes Kemenkes Palangka Raya dalam hal ini unit penelitian dan pengabdian masyarakat beserta tim pelaksananya, Jurusan/Prodi DIV Keperawatan, Pimpinan Puskesmas Pahandut, beserta Kader Posyandu Lansia Rindang Benua.

Kegiatan pengabdian masyarakat menggunakan metode pendidikan kesehatan dengan cara ceramah dan diskusi. Langkah-langkah sebagai berikut:

1. Menciptakan suasanan pertemua yang baik

2. Proses pendidikan kesehatan akan dibagi menjadi 2 kelompok. Kelompok pertama sasarannya adalah Lansia selanjutnya kelompok kedua sasarannya adalah keluarga lansia. Pada kelompok Lansia akan diberikan pendidikan kesehatan terkait konsep Lansia serta masalah-masalah kesehatan yang akan di hadapi pada masa Lansia akibat dari adanya penurunan fungsi tubuh pada masa Lansia. Sedangkan pada keluarga Lansia akan diberikan pendidikan kesehatan terkait peran keluarga tentang kemandirian Lansia dalam pemenuhan aktivitas sehari-hari.

3. Selanjutnya pemateri akan mengajukan permasalahan pada masing-masing kelompok untuk didiskusikan oleh kelompok dan pemateri terkait pemecahan masalah tersebut, tujuannya agar dapat melihat seberapa jauh pemahaman peserta terhadap materi yang disampaikan.

4. Selanjutnya dari hasil diskusi kelompok, peserta dan pemateri akan mengidentifikasi pilihan tindakantindakan yang diambil oleh kelompok untuk penyelesaian masalah tersebut. 
5. Setelah diidentifikasi tindakan yang di ambil oleh masing-masing kelompok pemateri memberikan komentar dan juga memberikan kesempatan kepada kelompok berkomentar maupun bertanya.

6. Setelah materi disampaikan, pemateri bersama dengan kelompok menetapkan tindak lanjut dari hasil pendidikan kesehatan yang sudah diberikan.

\section{HASIL DAN PEMBAHASAN}

Berdasarkan hasil pertemuan pertama kali dengan pengurus kader Posyandu Lansia Rindang Benua, kader terlihat antusias untuk berkerja sama dengan tim pengabdian masyarakat dalam pemberikan pendidikan kesehatan mengenai pemberdayaan keluarga tentang kemandirian lansia dalam pemenuhan aktifitas seharihari. Kegiatan ini dihadari oleh 30 peserta yang terdiri dari keluarga dan lansia yang terdaftar di Posyandu Lansia Rindang Benua dengan kehadiran 100\% mengikuti dari awal sampai selesainya pelatihan.

Evaluasi yang dilakukan dalam pengabdian masyarakat ini ada dua: Evaluasi pre-test dan post-test yaitu pada kegiatan hasil pre-test dari 30 peserta hasil $45 \%$ baik dan 55\% kurang baik setelah proses kegiatan dilakukan posttest memperoleh nilai 90\% baik dan 10\% kurang baik. Berdasarkan hasil dari pre-test dan post-test menunjukkan 90\% peningkatan pengetahuan keluarga tentang pemberdayaan keluarga tentang kemandirian lansia dalam pemenuhan aktifitas sehari-hari dengan metode ceramah dan diskusi. Target pelaksanaan berarti tercapai, keluarga yang telah diberikan pendidikan kesehatan diharapkan dapat menerapkan dalam kehidupan sehari-hari.

Keberhasilan pelaksanaan kegiatan ini telah sesuai dengan rencana dan harapan yang diinginkan dalam peningkatan kesadaran keluarga terhadap kemandirian lansia dalam pemenuhan aktifitas sehari-hari karena bersadarkan hasil penelitian peningkatan pengetahuan mengenai dukungan keluarga yang baik serta kesadaran lansia dalam kemandirian melakukan aktifitas seharihari akan meningkatkan kualitas hidup lansia dalam masa tuanya.

Kemandirian didefinisikan sebagai kemampuan individu untuk memenuhi kebutuhan hidup dengan tidak tergantung pada orang lain. Selain itu kemandirian diartikan sebagai suatu keadaan dimana seseorang berupaya untuk memenuhi segala tuntutan kebutuhan hidup dengan penuh tanggung jawab terhadap apa yang akan dilakukannya (Selantoro et al., 2011). Kemandirian fungsional bermakna mampu dan mau melakukan aktivitas sehari-hari tanpa bantuan orang lain. Aktivitas yang dikategorikan dalam kemandirian fungsional yaitu, mandi, makan, kontinen, berpindah, toileting, dan berpakaian. Tingkat kemandirian dalam melakukan Aktivitas Kehidupan Sehari-hari (AKS) merupakan salah satu faktor yang mempengaruhi kualitas hidup lansia ditambah dengan adanya peram keluarga yang memegang andil yang besar dalam pemberian perawatan lansia sehingga lansia dapat mempertahankan fungsi motorik dan kognitifnya (Alfyanita et al., 2016).

Kendala yang dirasakan dalam pelaksanaan pengabdian masyarakat ini yaitu menentukan jadwal kegiatan pengabdian masyarakat karena jadwal yang harus disamakan dengan jadwal Posyandu Lansia Rindang Benua. Selain itu, adanya bencana kabut asap akibat kebakaran hutan dan lahan yang sangat menganggu aktivitas pada saat pelaksanaan kegiatan sehingga harus dilakukan pengaturan ulang jadwal pelaksanaan setelah kabut asap hilang. Adapun dokumentasi untuk kegiatan pengabdian yang dilakukan disajikan pada Gambar 1 sampai 4. 


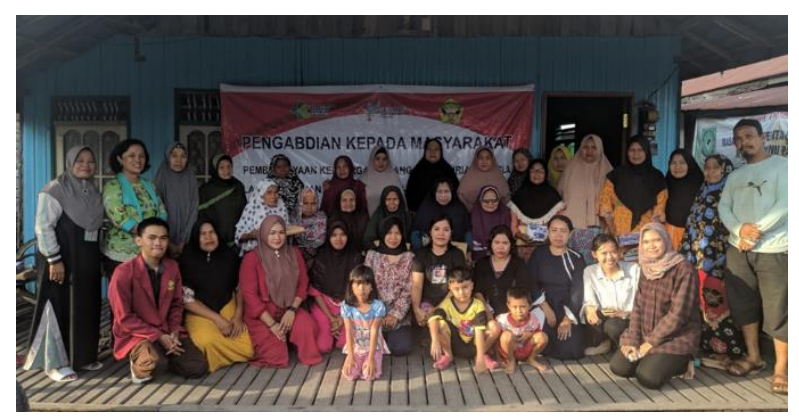

Gambar 1. Tim Pelaksanaan Pengabdian Masyarakat bersama Kader dan masyarakat di Posyandu Rindang Benua

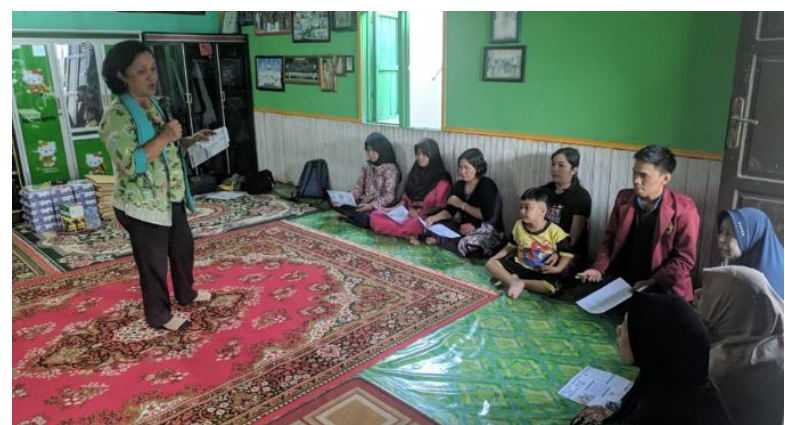

Gambar 2. Kegiatan pendidikan kesehatan di kelompok keluarga dengan lansia tentang peran keluarga dalam kemandirian lansia dalam pemenuhan aktifitas sehari-hari

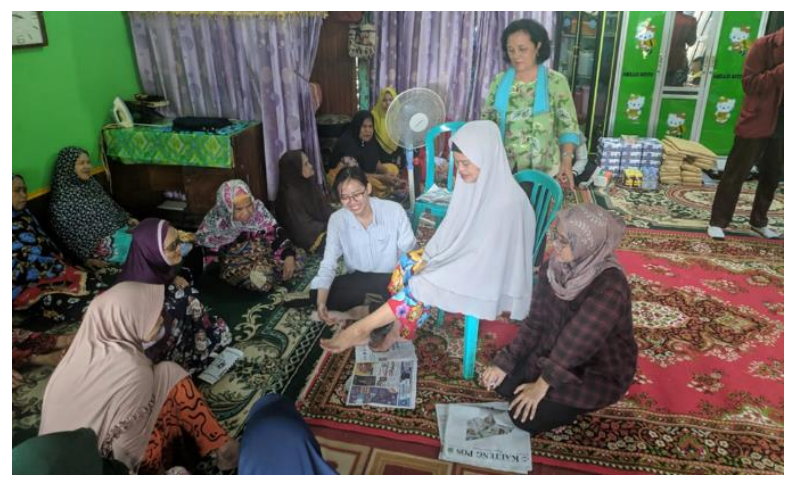

Gambar 3. Pemberian materi kesehatan pada di kelompok lansia tentang senam kaki

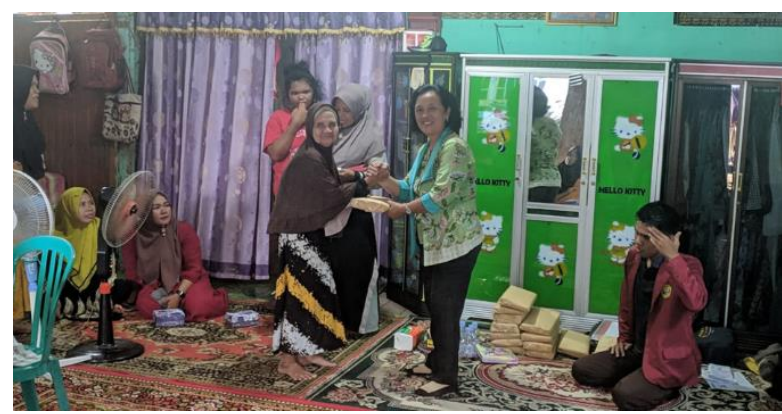

Gambar 4. Pemberian souvenir dan lealet pada lansia dan keluarga yang telah mengikuti kegiatan

\section{KESIMPULAN}

Adanya peningkatan pengetahuan peserta setelah dilakukannya pemberdayaan keluarga tentang kemandirian lansia dalam pemenuhan aktifitas seharihari. Semua peserta dalam kegiatan pengabdian masyarakat dapat mengerti dan memahami peran keluarga tentang kemandirian lansia dalam pemenuhan aktifitas sehari-hari. Disarankan agar kegiatan penyuluhan mengenai pemberdayaan keluarga tentang kemandirian lansia dalam pemenuhan aktifitas seharihari dapat dipantau untuk melihat keefektifan dalam segi perilaku keluarga dan lansia dalam melakukan aktifitas sehari-harinya

\section{REFERENSI}

Affandi, M. 2009. Faktor-Faktor Yang Mempengaruhi Penduduk Lanjut Usia Memilih Untuk Bekerja. Journal of Indonesian Applied Economics. 3(2):99-110.

Afrizal, A. 2018. Permasalahan Yang Dialami Lansia Dalam Menyesuaikan Diri Terhadap Penguasaan Tugas-Tugas Perkembangannya. Islamic Counseling: Jurnal Bimbingan dan Konseling Islam. 2(2):91-106. http://dx.doi.org/10.29240/jbk.v2i2.462

Alfyanita, A., Martini, R.D., Kadri, H. 2016. Hubungan Tingkat Kemandirian dalam Melakukan Aktivitas Kehidupan Sehari-Hari dan Status Gizi pada Usia Lanjut di Panti Sosial Tresna Werdha Sabai Nan Aluih Sicincin. Jurnal Kesehatan Andalas. 5(1):201-208. https://doi.org/10.25077/jka.v5i1.469

Badan Pusat Statistik. 2010. Statistik Indonesia 2010. Jakarta: Badan Pusat Statistik.

Ginting, D., Brahmana, N.E. 2019. Hubungan Dukungan Keluarga Dengan Keaktifan Lansia Mengikuti Kegiatan Posyandu Di Desa Lumban Sinaga Wilayah Kerja Puskesmas Lumban Sinaga Kecamatan Pangaribuan Kabupaten Tapanuli Utara Tahun 2017. Journal of Healthcare Technoogy and Medicine. 5(1):72-85. https://doi.org/10.33143/jhtm.v5i1.327 
Kresnawati, I., Kartinah. 2012. Hubungan Dukungan Keluarga Dengan Keaktifan Lansia (Lanjut Usia) Dalam Mengikuti Kegiatan Di Posyandu Lansia Desa Gonilan Kecamatan Kartasura. Skripsi. Surakarta: Universitas Muhammadiyah Surakarta.

Kurnianto, D. 2015. Menjaga Kesehatan Di Usia Lanjut. JORPRES (Jurnal Olahraga Prestasi). 11(2):19-30. https://doi.org/10.21831/jorpres.v11i2.5725

Kushariyadi. 2010. Asuhan Keperawatan Pada Klien Lanjut Usia. Jakarta: Salemba Medika.

Maryam, R.S., Ekasari, M.F., Rosidawati, Hartini, T., Suryati, E.S., Noorkasiani. 2010. Asuhan Keperawatan pada Lansia. Jakarta: Trans Info Media.

Misnaniarti. 2017. Analisis Situasi Penduduk Lanjut Usia dan Upaya Peningkatan Kesejahteraan Sosial di Indonesia. Jurnal Ilmu Kesehatan Masyarakat. 8(2):67-73.

https://doi.org/10.26553/jikm.2016.8.2.67-73

Pramono, L.A., Fanumbi, C. 2012. Permasalahan Lanjut Usia di Daerah Perdesaan Terpencil. Kesmas: Jurnal Kesehatan Masyarakat Nasional = Kesmas: National Public Health Journal. 6(5):201-211. http://dx.doi.org/10.21109/kesmas.v6i5.85

Selantoro, E., Nazari, N., Humaira, C.S. 2018. Hubungan Kemandirian Lansia Dengan Stress Di UPTD Rumoh Seujahtera Geunaseh Sayang Ulee Kareng Kota Banda Aceh. Jurnal Aceh Medika. 2(1):109-118.

Sulandari, S., Martyastanti, D., Mutaqwarohmah, R. 2009. Bentuk-Bentuk Produktivitas Orang Lanjut Usia (Lansia). Indigenous: Jurnal Ilmiah Psikologi. 11(1):58-68. https://doi.org/10.23917/indigenous.v11i1.1 624

Yuningsih, R. 2019. Strategi Promosi Kesehatan dalam Meningkatkan Kualitas Sanitasi Lingkungan. Aspirasi: Jurnal Masalah-masalah Sosial. 10(2):107-118.

https://doi.org/10.46807/aspirasi.v10i2.1391 